\title{
Música popular, emoção e política: a batalha dos afetos
}

\author{
Eduardo Granja Coutinho'
}

\begin{abstract}
Resumo
Tendo como referência o debate teórico sobre a relação entre paixão e ideologia, este ensaio reflete sobre a maneira como a emoção suscitada pela música popular é orientada ideologicamente por diferentes sujeitos políticos. Numa perspectiva hegemônica, o Estado e a indústria da canção, cada um a seu modo, se alimentam dessa emoção ao incorporarem as formas musicais populares, colocando o sentir das massas à disposição de ideias e valores dominantes. Por outro lado, a música popular, como fonte da paixão, presta-se também à criação e expressão daquela ideologia democrática e historicista que Gramsci chamou de nacional-popular. Como exemplo dessa "estratégia sensível" das camadas populares, busca-se analisar, particularmente, a canção de protesto latino-americana dos anos 1960/1970.
\end{abstract}

\section{Palavras-chave}

Hegemonia; mito; paixão; emoção; música popular; canção de protesto; nueva canción

Popular music, emotion and politics: the battle of affections

\begin{abstract}
Taking as a reference the theoretical debate on the relationship between passion and ideology, this essay reflects on the way in which the emotion aroused by popular music is ideologically oriented by different political subjects. In a hegemonic perspective, the State and the song industry, each in their own way, are nourished by this emotion by incorporating popular musical forms, placing the masses' feelings at the disposal of dominant ideas and values. On the other hand, popular music, as a source of passion, also lends itself to the creation and expression of that democratic and historicist ideology that Gramsci called national-popular. As an example of this "sensitive strategy" of the popular strata, we seek to analyze, in particular, the Latin American protest song of the 1960s/70s.
\end{abstract}

\section{Keywords}

Hegemony; myth; passion; emotion; popular music; protest song

Artigo recebido: março de 2021

Artigo aprovado: maio de 2021 
Para Gallotti, que me apresentou Noel.

E para Augusto, Eide e Cristina, companheiros de solidariedade aos povos latino-americanos.

No hay revolución sin canciones.

Salvador Allende

Se os homens são movidos por sua paixão, como quer Hegel, o controle da paixão dos homens é uma poderosa arma política. Não seria essa a função da ideologia, transformar as ideias de uma classe em paixão, mito, orientando os sentimentos das massas para um determinado projeto de poder? Quando se apoderam dos indivíduos, isto é, quando são capazes de mobilizar suas emoções, essas ideias tornam-se "crença", base de sua ação política. Daí a importância que assumiram ao longo da história as diferentes formas de controle das paixões humanas. As religiões, o nacionalismo burguês, as ideologias do mercado (a paixão pelo dinheiro²) têm sido muito eficazes em utilizar os afetos populares para a conservação das relações de poder e propriedade. Já os que lutam por uma nova ordem têm sido postos em marcha pela paixão revolucionária: pela solidariedade que comove, pelo amor à liberdade, pelo sentimento de revolta, pelo ódio ao facínora. Não é, portanto, apenas no campo das ideias, da razão, que se trava a luta política, mas também no campo da sensibilidade, das emoções, do afeto. É no plano estético dos sentimentos, da experiência corporal, que os diferentes grupos sociais irão encontrar o vínculo que une os homens em torno de uma ideia, de um projeto. E, afinal, que vínculo, que fonte de coesão social, pode ser mais forte que a paixão? 


\section{Paixão e hegemonia}

Não são poucos os instrumentos de controle dos afetos de que dispõem as classes dominantes para infiltra-se na maneira de sentir de seus subordinados e construir sua hegemonia. Na cultura contemporânea, o futebol, as novelas, os seriados, os reality shows, a imprensa sensacionalista são formas extremamente eficazes em canalizar a emoção popular para o projeto hegemônico. Dentre essas formas, há uma que se destaca pela sua força, pelo seu enraizamento na tradição, pela sua capacidade de atuar sobre a sensibilidade das massas no sentido de suscitar emoções e produzir uma determinada vontade coletiva: a música.

Por seu apelo direto aos instintos e às paixões subjetivas, a música tem sido ao longo da história instrumentalizada pelos grupos dominantes, prestando-se à estetização da política. Pense-se, por exemplo, na importância da música sacra na liturgia cristã, na força ideológica dos hinos ou, ainda, no significado da música folclórica no contexto de ascensão do nacionalismo europeu no século XIX. Naquele momento, a publicação de canções populares, então "descobertas", constituiu um importante instrumento forjador da mitologia nacionalista indispensável à construção dos Estados modernos. Tais "tradições inventadas" foram capazes de evocar um sentimento de solidariedade numa população dispersa, privada de instituições nacionais tradicionais. Elas conferiam às nações em formação o necessário sentido de transcendência, responsável pelo patriotismo e pela imaginação nacionalista. Nesse movimento, a emoção popular presente nas canções folclóricas, que encarnavam, supostamente, o "espírito do povo", foi incorporada como fundamento da identidade nacional. Como observa o musicólogo nacionalista Mozart de Araújo, quaisquer que sejam os processos ou tipos de formação de uma música nacional erudita, o que está na base dela é o elemento folclórico, pois, se é verdade que a música popular não desperta, como a música erudita, o interesse estético puro, por outro lado, "a música erudita jamais expressaria como 
a música popular os caracteres afetivos e emocionais de uma comunidade nacional" (1992, p.48; grifo meu).

No Brasil, o regime de Vargas promoveu, intensamente, o pathos nacionalista da música popular como parte de sua estratégia de controle sobre a sociedade: estimulou o canto orfeônico, que conjugava disciplina, civismo e educação musical; ofıcializou o Carnaval e incentivou o samba de exaltação nacionalista. Herdeiro da tradição ufanista e em sintonia com o Hino Nacional Brasileiro, o samba de exaltação veicula o mito verde-amarelo, as fábulas do Brasil "gigante", "heróico", "risonho", "florido" e abençoado por Deus. Esse mito é expresso, emblematicamente, no primeiro e mais famoso samba do gênero, encomendado, por sinal, pelo próprio Vargas: o "Aquarela do Brasil" (1939), de Ari Barroso. É o próprio compositor quem se refere à sua intenção de conferir ao samba uma emoção nacionalista:

Senti, então, iluminar-me uma ideia: a de libertar o samba das tragédias da vida [...]. Fui sentindo toda a grandeza, o valor e a opulência da nossa terra, 'gigante pela própria natureza'. Revivi, com orgulho, a tradição dos painéis nacionais e lancei os primeiros acordes, vibrantes, aliás. [...] De dentro de minh'alma, extravasara um samba que eu há muito desejara, um samba que, em sonoridades brilhantes e fortes, desenhasse a grandeza, a exuberância da terra promissora, da gente boa, laboriosa e pacífica, povo que ama a terra onde nasceu. Esse samba divinizava, numa apoteose sonora, esse Brasil glorioso (apud CABRAL, s/d, p.179).

Ao incorporar o samba, submetendo a fala histórica dos grupos subalternos ao ideário nacionalista, Vargas se apropria de uma linguagem popular, que suscitava uma certa emoção. Mas esvazia essa fala de seu conteúdo histórico, atribuindo-lhe uma nova significação, um novo pathos. Parafraseando Roland Barthes, podese dizer que o pathos do samba de exaltação é uma emoção roubada e resignificada na perspectiva ideológica dominante. A fala malandra e marginal dos grupos proletários, com a sua emoção característica, 
é como que distorcida pela fala mítica nacionalista. Nesse processo, a sensibilidade popular se desvincula de uma consciência histórica potencialmente contra-hegemônica.

Mas não é apenas do pathos nacionalista que se alimenta a ideologia burguesa. O uso político dos afetos se dá de diversas maneiras. $\mathrm{Na}$ indústria da canção, a emoção se reduz, frequentemente, ao mero sentimentalismo romântico, que coloca o sentir das massas à disposição de ideias e valores dominantes. Abordando os temas do amor e da paixão numa perspectiva idealizante e fatalista, a canção de consumo atua politicamente no sentido de obscurecer ou impedir uma consciência crítica da questão social, realizando aquilo que Lukács chamou de "apologia indireta do existente". Pense-se nas canções sentimentais $^{3}$ de Custódio Mesquita nos anos 1930/40 ou nas de Roberto Carlos durante a ditadura. Apaziguadoras, sedantes, consoladoras, essas canções não instalam qualquer contradição: aplainam os sentimentos e põem seu ouvinte em suave sintonia com o mundo capitalista ${ }^{4}$. Reproduzindo o modelo de comportamento, aspirações e ideais hegemônicos (consumismo, individualismo e exaltação da vida privada), a música romântica de evasão subjetivista é a resposta mais efetiva da indústria cultural à canção que vem de baixo, carregada de emoções, ameaçando o sistema simbólico dominante.

Desde o início do século XX, a música dita "de massa" é um meio privilegiado de construção da hegemonia cultural norte-americana. Com o ragtime, o charleston, o one-step, o two-step, o fox-trot, difundidos inicialmente pelo disco e, mais tarde, pelo cinema, começamos a cantar, dançar, sentir e pensar como os norte-americanos. Junto com essas formas de entretenimento e sensibilidade vinha contrabandeada, como se sabe, uma visão de mundo. Após a Segunda Guerra Mundial, essa hegemonia se consolida com o rock'n roll. Tin Pan Alley e Hollywood - as fábricas de sonho do mundo capitalista - informavam o sentimento das massas nos quatro quadrantes do planeta, substituindo a emoção e a memória da canção popular de cada país e re- 
gião pela audição emotiva da pop music. A dominação política se fazia acompanhar de uma imposição estética. Na era da cultura de massa, o imperialismo controla a música nas áreas onde exerce o seu domínio.

Esse controle envolve a domesticação pela indústria das falas regionais dissonantes, críticas, contestatórias, como o próprio rock. Ao serem assimiladas ao star sistem, essas falas deixam de expressar uma historicidade alternativa, subalterna, perdendo suas características "explosivas". Como assinala Edgar Morin, o próprio de todo esse sistema da cultura de massa é o de circunscrever a tendência dionisíaca, mas sem destruí-la; é o de abafar o subversivismo latente, de maneira a explorá-lo e integrá-lo, descartando toda a tendência rebelde incontrolável (1965). Circunscrever a emoção da música do povo sem suprimi-la, submetendo-a à ideologia do mercado: eis o procedimento típico da indústria da canção.

Os registros visuais de jovens gritando histericamente e desmaiando nos shows dos ídolos da juventude, como Elvis Presley, dão a medida de como a emoção, galvanizada pela música, torna-se pura passionalidade, apartada de qualquer consciência crítica. Esse tipo de catarse, por mais explosiva que seja, mantida sob o controle da indústria, não significa, certamente, uma ameaça à ordem burguesa. Pelo contrário, uma tal liberação emocional, no âmbito do espetáculo, apenas garante que a paixão da juventude, sob a forma da idolatria, conserva os jovens - rebeldes sem causa - ainda mais firmemente na linha.

\section{Paixão e contra-hegemonia}

Vimos até aqui que a música popular, por sua capacidade de arrebatar o ouvinte para o estado de espírito desejado, tem sido um instrumento privilegiado da hegemonia burguesa. Mediante a ação racional, discursiva de um sujeito, seja da mídia, seja do Estado, a emoção desencadeada pela música se torna ideologia, uma espécie de religião que vai direto ao coração das pessoas comuns. Note-se, contudo, que em contraposição a esse uso da emoção popular pelos grupos hege- 
mônicos, a música popular, como fonte da paixão, presta-se também à criação e expressão daquela ideologia democrática e historicista que Gramsci chamou de nacional-popular.

Nos textos gramscianos, o nacional-popular aparece como uma estratégia político-cultural das classes subalternas. Ele significa a possibilidade desses grupos reelaborarem o passado histórico-cultural da nação - as formas históricas, portadoras de ideias e afetos - a partir de sua própria perspectiva, isto é, de refazer a memória social num sentido contrário ao da classe dirigente ${ }^{5}$. São, assim, representantes dessa visão de mundo "os artistas e intelectuais que souberam representar a realidade de seu país sob um viés popular, conjugando indissoluvelmente a grandeza estética com um profundo espírito popular e democrático" (COUTINHO, 2011, p. 104).

Assim entendido, o conceito gramsciano designa, fundamentalmente, uma articulação orgânica entre os intelectuais e o povo-nação, o que implica no estabelecimento de um processo de educação mútua. O intelectual orgânico das classes subalternas - não necessariamente oriundo dessas classes, mas organicamente ligado a elas - é um intérprete dos seus sentimentos, capaz de elaborá-los conscientemente. Dessa articulação dialética entre sentir e saber depende a criação de uma vontade coletiva nacional-popular.

Nos Cadernos do cárcere, a elaboração da paixão pela consciência, isto é, a passagem do momento passional ao momento ético político é defınida por Gramsci como “catarse” (1999, v. 1, pp. 314-315). Esse processo é aquele em que a classe trabalhadora adquire consciência de si, percebendo-se como sujeito histórico. A fixação do momento catártico parece-me fundamental para entendermos o processo de formação da consciência nacional-popular. Nesse processo, a passagem do sentir ao saber de que fala Gramsci coincide com a passagem dialética do sentimento de nacionalidade à consciência popular, de classe; a emoção contida nas formas da cultura nacional é reelaborada sob um viés contra-hegemônico. A visão de mundo nacional-popular aparece, 
assim, como uma forma de conhecimento crítico, coerente, que ecoa os gemidos, os risos, as lágrimas, os gritos de protesto da nação.

Diferentemente, portanto, da "catarse" promovida pela indústria cultural, que significa a passagem do sentir das massas à ideologia do mercado, a catarse nacional-popular consiste na passagem das emoções populares à autoconsciência dos grupos subalternos. Nessa transformação da paixão em ideologia, o sentimento torna-se compreensão e saber.

Tome-se o samba como exemplo do vigor da cultura nacional-popular. Herdeira da música dos terreiros - do xirê (a roda dançante) essa batida faz aflorar emoções físicas incrivelmente poderosas. Seu ritmo quente que, como cantaram os sambistas, fica ainda mais ardente quando vem da alma de nossa gente ${ }^{6}$, articula-se à consciência histórica de um grupo social marginalizado; é portador de uma memória, de uma sabedoria popular que permanece na história, comunicando sentimento, ideias e valores subalternos (cf. COUTINHO, 2011, pp. 143-151). Há um século, essa emoção é apropriada pela indústria do entretenimento, dando origem, não raro, a formas de samba que não expressam aquela historicidade subalterna, como é o caso do "sambolero" ou do chamado "pagode romântico paulista". Encontra-se nessas formas mercadológicas, é certo, algo da emoção do samba, mas o seu conteúdo histórico - o seu saber - se dissolveu nos sistemas de produção e representação da cultura de massa. Contudo, o samba, resiliente, cultivado em seus redutos, nunca deixou de servir às "estratégias sensíveis" dos grupos marginalizados e expressar sua identidade cultural. Devido à sua íntima união com a vida das camadas baixas da população, vale dizer, ao seu caráter nacional-popular, o samba aparece, desde os tempos de Sinhô, como expressão de uma visão de mundo democrática no plano da cultura popular.

\section{La nueva canción latino-americana}

Numa passagem dos Cadernos do cárcere, Gramsci notou que o que distingue o canto popular, no quadro de uma nação e de sua cul- 
tura, é o "seu modo de conceber o mundo e a vida, em contraste com a sociedade oficial" (2002, v.6, p. 181).

Sem fugir ao espírito da teoria gramsciana, poderíamos acrescentar que este canto adquire um caráter crítico, transformando-se em protesto e propaganda política, no momento em que os intelectuais de esquerda reinterpretam as formas da tradição, que exprimem a emoção e a consciência popular, atribuindo-Ihes significação libertária.

A maioria dos compositores de protesto, oriundos da classe média e com nível de escolaridade elevado, se aproxima das massas com a intenção de desenvolver a sua consciência política, seja de forma paternalista, tentando impor uma cultura revolucionária a partir do exterior, seja de forma orgânica, buscando uma relação de aprendizado mútuo com os artistas populares do campo e da cidade. Poderíamos dizer, esquematicamente, que nesse encontro entre uma cultura letrada e a cultura popular, os intelectuais entram com o conteúdo e o povo com a linguagem e os afetos. De fato, os chamados compositores de protesto se apropriam de uma linguagem tradicional para fazer chegar ao povo, nessa linguagem que é sua, e por meio desses afetos que são seus, uma visão de mundo crítica.

Essa aproximação entre os intelectuais e a tradição popular é uma das características da música de protesto latino-americana, que nos anos 1960 e 1970 constituiu-se como uma das principais formas de criação e afırmação da autoconsciência dos povos do continente. Basta pensar na produção de artistas como a argentina Mercedes Sosa; os chilenos Violeta Parra, Victor Jara, Rolando Alarcón e os grupos Quilapayún e Inti-Illimani; os venezuelanos Ali Primera e Soledad Bravo; os cubanos Carlos Puebla, Pablo Milanes, Silvio Rodriguez; o uruguaio Daniel Viglietti, os brasileiros Carlos Lyra Geraldo Vandré, Nara Leão, Zé Keti, Chico Buarque e tantos outros que cantaram e contaram a história dos povos da América Latina na perspectiva dos vencidos.

Nas mais diversas linguagens, gêneros, ritmos e estilos tradicionais, a canção de protesto latino-americana insiste num conteúdo libertário 
e participante, abordando diretamente o problema do subdesenvolvimento e das condições de vida do povo, e afırmando a tradição de luta dos antepassados, o exemplo deixado pelos combatentes mortos, a identidade determinada pela história comum. Tradição legada por revolucionários como o poeta José Martí que, no início do século XX, escreveu os versos, musicados por Joseíto Fernández que se tornariam, mais do que um símbolo da Revolução Cubana, uma expressão maior do pathos da luta pela emancipação latino-americana: "La guantanamera". Tradição afırmada por compositores que, em suas canções, recuperaram sentimentos, personagens, fatos, ideias, valores, práticas, símbolos da história latino-americana, recriando a identidade dos oprimidos, como na canção de Carlos Puebla "Hasta siempre, comandante" (1965):
Aquí se queda la clara,
La entrañable transparencia,
De tu querida presencia
Comandante Che Guevara... ${ }^{7}$

Foi a partir do sucesso dessa guajira (gênero rural cubano) que Carlos Puebla fundou o Centro de la Canción Protesta, onde floresceu o movimento conhecido como a Nova Trova Cubana, no qual surgiram vozes como Pablo Milanés, Silvio Rodriguez e Vicente Feliú. Pouco antes, em 1963, divulgou-se em Mendoza, na Argentina, o Manifiesto del Nuevo Cancionero, que sistematizou as diretrizes da canção de protesto naquele país. O Manifesto foi escrito pelo poeta Armando Tejada Comez e assinado por catorze artistas entre os quais Mercedes Sosa, que se tornaria a intérprete mais conhecida da canção engajada latino-americana. Movimentos semelhantes ocorriam em toda a América Latina sob o nome genérico de nueva canción. No Brasil, o movimento era representado pelos compositores de protesto herdeiros da bossa-nova, ligados ao CPC da UNE.

A despeito da almejada unidade cultural latino-americana, sonhada desde o século XIX - sonho que entre os anos 1950 e 1970 voltava a mo- 
tivar os movimentos que fervilharam pelo continente -, a nueva canción era, na verdade, a música nacional-popular de cada país. Mesmo expressando um conteúdo de ideias parecido - defesa da reforma agrária, crítica do imperialismo norte-americano, recusa dos valores do mundo capitalista, etc. - a forma, isto é, a linguagem musical assumida por essa nueva canción variava de região para região. Ela podia assumir a forma de uma guajira, de uma cumbia, de um samba, de uma toada, de uma zamba, etc. de acordo com a música folclórica ou popular dos diferentes países.

O caráter nacional-popular da nueva canción argentina é explicitado pelo próprio Manifiesto del Nuevo Cancionero, que assim dizia:

A busca por uma música nacional de conteúdo popular tem sido e é um dos mais caros objetivos do povo argentino. O "Manifiesto" aglutinou um sentimento nacionalista, libertário e de oposição às elites oligárquicas tradicionais, à medida que defendia a música popular como veículo de identidade cultural e política dos excluídos, valorizando regionalismos, promovendo a produção independente e resistindo à imitação musical de obras estrangeiras (COMEZ, 1963).

Diferentemente do nacionalismo musical "pelo alto", incentivado pelo Estado, o Manifiesto propõe a assimilação criativa das expressões tradicionais da música popular, "não para roubar o tesouro do povo", e sim para "valorizar, aprofundar e desenvolver a arte popular", buscando "integrar o cancioneiro popular ao desenvolvimento criador do povo todo para acompanhá-lo em seu destino, expressando seus sonhos, suas alegrias, suas lutas e suas esperanças" (COMEZ, 1963).

Nessa mesma perspectiva, Violeta Parra percorreu sua terra para encontrar os antigos cantadores, a fim de trocar com eles conhecimentos, aprender a sua linguagem e extrair de sua história o conteúdo do seu próprio canto. Nos anos 1950, antes mesmo da voga do protesto na América Latina, a cantora realizou importante trabalho como pesquisadora de ritmos, danças e músicas chilenas, chegando a catalogar cerca de três mil canções folclóricas. Da elaboração desse can- 
cioneiro tradicional, base de sua criação, nasce, em 1961, as músicas "¿Qué dirá el Santo Padre?", "Arauco tiene una pena" e "Miren cómo sonríen", marcos do início da nueva canción chilena. Por seu pioneirismo, e pela força de suas composições, Violeta Parra é considerada a mãe da música de protesto em nosso continente.

Com os dentes do imperialismo cravados na garganta, como escreveu Galeano, os povos latino-americanos tiveram na música um dos principais instrumentos forjadores de sua subjetividade política. Sob a influência da vitória dos guerrilheiros cubanos, a nueva canción expressou, da maneira mais direta e inequívoca, o sentimento de latino-americanicidade, a emoção revolucionária, a "fantasia concreta" que, como disse Gramsci, "atua sobre um povo disperso e pulverizado para despertar e organizar sua vontade coletiva" (1999, v. 3, p. 14).

Pense-se, por exemplo, na canção "El pueblo unido jamás será vencido" (1973) ${ }^{8}$. Composta inicialmente como um hino da Unidade Popular que deu sustentação ao governo socialista de Salvador Allende, essa música transformou-se, logo após o golpe de Estado, em um hino da resistência à ditadura chilena. Seus versos mais conhecidos, que dão nome à canção, são cantados ainda hoje em manifestações populares em toda a América Latina. Trata-se de um "mito" - no sentido soreliano da palavra ${ }^{9}$-, capaz de evocar a massa de sentimentos e a fé na vitória necessárias ao levante popular:

De pie, cantar

Que vamos a triunfar

Avanzan ya

Banderas de unidad

Y tú vendrás

Marchando junto a mí

Y asi verás

Tu canto y tu bandera florecer

La luz

De un rojo amanecer

Anuncia ya la vida que vendrá. 
A luta dos povos latino-americanos contra o imperialismo e seus sócios nacionais foi, como disse Patricio Guzmán em seu belo documentário sobre o governo Allende, "a luta de um povo sem armas"10. $\mathrm{Na}$ verdade, o filme nos mostra que os trabalhadores chilenos tinham como única arma uma sólida cultura revolucionária, fortalecida pelas brigadas culturais, às quais pertenciam artistas, poetas e músicos, como Victor Jara, o compositor-mártir do ciclo militar latino-americano. Essa cultura, entretanto, não foi suficiente para conter os tanques do general Pinochet e os caças estadunidenses que bombardearam o Palácio de La Moneda. A arma da crítica, mesmo tendo se apoderado das massas de uma forma impressionante, não pôde substituir a crítica das armas. Porta-voz musical da Unidade Popular, Victor Jara foi preso poucos dias depois do golpe que destituiu Salvador Allende, teve seus pulsos quebrados e morreu fuzilado, cantando: Venceremos, venceremos, mil cadenas habrá que romper...".

Jara e tantos outros cantadores revolucionários haviam entendido a importância da estética no processo político, sabiam que para chegar às massas a teoria deveria tocar-lhes o coração. Compreendiam também que a música apropriada para embalar os movimentos sociais na América Latina, criando uma atmosfera emocional propícia, não deveria ter o pathos da música pop, nem o da canção nacionalista, nem mesmo o da contracultura musical. O pathos da nueva canción, buscado na cultura tradicional do continente, deveria ter qualquer coisa do sentimento profundo dos povos originários, do amor reverencial à Pachamama; deveria ter qualquer coisa que nos fizesse sentir herdeiros da luta de Bolívar e Artigas pela Pátria Crande; deveria exprimir o sentimento de revolta dos índios contra os invasores e dos escravos negros contra os senhores das minas e dos engenhos. A nova música deveria expressar a coragem e a ternura de Che Guevara.

Emblemática dessa fala afetuosa que depois de tanto tempo ainda faz aforar a paixão revolucionária dos povos latino-americanos, unindo sentimentos, pensamentos e vontade, é a canção "Gracias a la vida", 
de Violeta Parra. Seus versos têm o poder de dar àqueles que o entoam um entusiasmo e uma esperança extraordinários.

Cracias a la vida que me ha dado tanto

Me ha dado la risa y me ha dado el llanto

Asi yo distingo dicha de quebranto,

Los dos materiales que forman mi canto,

Y el canto de ustedes que es mi mismo canto,

Y el canto de todos que es mi propio canto

Gracias a la vida que me ha dado tanto...

\section{Referências}

ARAÚJO, Mozart de. Rapsódia brasileira. Fortaleza: Universidade do Ceará, 1992. BARROS, Orlando de. Custódio Mesquita, um compositor romântico: o entretenimento, a canção sentimental e a política no tempo de Vargas, 19301945. Tese de doutoramento. São Paulo: USP/História, 1995.

CABRAL, Sérgio. No tempo de Ari Barroso. Rio de Janeiro: Lumiar, s/d.

CHAUÍ, Marilena. "Considerações sobre o nacional-popular". In.: Cultura e democracia no Brasil. São Paulo: Cortez, 1990.

COUTINHO, Carlos Nelson. Cultura e sociedade no Brasil: ensaios sobre ideias e formas. São Paulo: Expressão Popular, 2011.

COUTINHO, Eduardo Granja. A paixão segundo Antonio Gramsci. Rio de Janeiro: Mórula, 2020.

COUTINHO, Eduardo Granja. Velhas histórias, memórias futuras: o sentido da tradição em Paulinho da Viola. 2. ed. Rio de Janeiro: Editora da UFRJ, 2011.

GOMEZ, Armando Tejada. Manifiesto Fundacional del Movimiento del Nuevo Cancionero, 1963. Disponível em: https://academic.uprm.edu/dgonzalez/latinoamericana/Manifiesto\%20fundacional\%20de.pdf

GRAMSCI, Antonio. Cadernos do cárcere (v. 1, 3 e 6). Rio de Janeiro: Civilização Brasileira, 1999-2002.

INSTITUTO VLADIMIR HERZOG. http://memoriasdaditadura.org.br/musica-engajada-na-america-latina/

MORIN, Edgar. "On ne connaît pas la chanson". In.: Communications (Chansons et disques). Paris: Seuil, 1965. 


\section{Notas}

1 Professor titular da Escola de Comunicação da Universidade Federal do Rio de Janeiro (UFRJ). Doutor e Mestre em Comunicação pela Escola de Comunicação da UFRJ. Coordena o Grupo de Estudos Marxistas de Comunicação e Cultura (Cemccult), cadastrado no CNPq. Brasil. ORCID: https://orcid.org/0000-0002-1089252X. E-mail: edugraco8@gmail.com

2 Auri sacra fames ("maldita fome de ouro"), expressão com a qual o poeta Virgílio condena a ambição desmedida dos homens.

3 Não me refiro, evidentemente, a qualquer canção sentimental, mas àquelas em que o amor é desistoricizado, ao contrário do que acontece, por exemplo, nas canções de amor de Noel Rosa, Discépolo, Paulinho da Viola, Nina Simone, Ceorges Brassens etc.

4 Sobre o caráter político da música romântica de Custódio Mesquita no governo Vargas, cf. Barros (1995).

5 No caso específico italiano, o nacional-popular é uma resposta ao nacionalismo burguês em sua forma histórica mais exacerbada, o fascismo. Sobre o conceito de "nacional-popular", cf. Marilena Chauí (1990).

6 "Apoteose ao samba" (Silas de Oliveira e Mano Décio da Viola, 1974).

7 O título da canção "Hasta siempre, comandante" ecoa a frase final da famosa carta de despedida de Guevara: "Hasta la victoria siempre, „Patria o muerte!".

8 "El pueblo unido jamás será vencido" (junho de 1973), música de Sergio Ortega e letra do grupo Quilapayún.

9 Sobre a categoria de "mito" presente no pensamento de Georges Sorel e sua reelaboração por autores como Gramsci e Mariátegui, cf, Eduardo G. Coutinho (2020).

10 A batalha do Chile: a luta de um povo sem armas. (Patrício Guzmán, 1972-1979). Realizado no exílio, a trilogia aborda três momentos da história contemporânea do Chile: "A insurreição da burguesia", "O golpe de Estado" e "O poder popular".

11 "Venceremos" (Claudio Iturra, Sérgio Ortega, 1970). Essa e outras canções de resistência política foram, evidentemente, censuradas pelos governos ditatoriais da América Latina. No Chile, tal era a identificação da nueva canción chilena com o governo deposto da Unidade Popular, que o general Pinochet proibiu os instrumentos típicos desse movimento, como a charango (cordas) e a zampoña (sopro). 


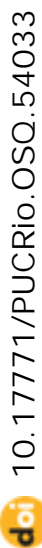

